\title{
A five years retrospective analytic study of maternal deaths at tertiary care centre, Gujarat, India
}

\author{
Manthan Patel*, Kamal Goswami, Shetal Prajapati, Dolly Chavda
}

Department of Obstetrics and Gynaecology, P. D. U. Medical College, Saurashtra University, Rajkot, Gujarat, India

Received: 25 June 2016

Accepted: 12 July 2016

\section{*Correspondence:}

Dr. Manthan Patel,

E-mail: drmanthanpatel111@gmail.com

Copyright: ( ) the author(s), publisher and licensee Medip Academy. This is an open-access article distributed under the terms of the Creative Commons Attribution Non-Commercial License, which permits unrestricted non-commercial use, distribution, and reproduction in any medium, provided the original work is properly cited.

\section{ABSTRACT}

Background: Maternal mortality is one of the major challenges which face the developing countries throughout the world. The aim of the study is to assess the causes of maternal mortality at P.D.U. Medical College, and to identify the avoidable ones.

Methods: Data were collected from records of patients who presented to and/or delivered at P.D.U. Medical College between 2011 and 2015. Only cases of maternal mortality were included in this study. In our study, we found 120 maternal deaths at our hospital between 2011 and 2015.

Results: We found that the indirect causes of maternal mortality accounted for $29.3 \%$ of all mortalities. The leading cause of death in the 5 years was uncontrollable postpartum haemorrhage $(23.3 \%)$, preeclampsia with its complications (15.8\%), Anemia (14.1\%), Abruption placentae 12.5\% and Septicaemia 5\% .Direct maternal deaths accounted for $70.7 \%$.

Conclusions: Preeclampsia and PPH, as well as their complications are the leading causes of death in one of the biggest tertiary care university hospitals in Egypt. However, there are other important avoidable predisposing factors that should be dealt with including lack of patient education, delayed transfer from other hospitals, and substandard practice.

Keywords: Maternal deaths, Facility based maternal death review, Maternal death audit, Maternal mortality

\section{INTRODUCTION}

Maternal mortality is one of the major challenges which face the developing countries throughout the world. According to the tenth revision of the international classification of diseases (ICD-10) it is defined as the death of a woman while pregnant or within 42 days of termination of pregnancy, irrespective of the duration and to the site of the pregnancy, from any cause related to or aggravated by the pregnancy or its management but not from accidental or incidental causes. ${ }^{1}$ The 42 -day limit is somewhat arbitrary, and in recognizing the fact that modern life-sustaining procedures and technologies can delay death, ICD-10 introduced a new category, namely the late maternal death, which is defined as the death of a woman out of direct or indirect obstetric causes more than 42 days but less than one year after the termination of pregnancy. ${ }^{2}$ Maternal mortality ratio is defined as the number of women who died while pregnant or within 42 days of termination of pregnancy per 100,000 live births. ${ }^{3}$

Maternal deaths are divided into two groups. The first group is the direct obstetric deaths which result from obstetric complications during pregnancy, labour and the puerperium, or resulted from interventions, and any incorrect treatment received. The second group is the indirect deaths which are the result from previous existing disease or disease that developed during pregnancy and which were not due to direct obstetric causes, but was aggravated by physiologic effects of pregnancy. 4 
Deaths from "accidental or incidental" causes have historically been excluded from maternal mortality statistics.

According to the WHO, $80 \%$ of maternal deaths in developing countries are due to direct maternal causes such as haemorrhage, sepsis and hypertensive disorders. Additionally, indirect causes such as HIV/AIDS, cardiac diseases, hepatic diseases and anemia account for the remaining $20 \%$ of maternal deaths. ${ }^{5}$ Of the 287,000 deaths due to pregnancy or childbirth complications that occur each year worldwide, $85 \%$ are in Africa and Asia alone. ${ }^{4}$

As $90 \%$ of maternal deaths are preventable, access to good quality essential obstetrical care can prevent $48 \%$ of maternal deaths at time of delivery. ${ }^{7}$ It is cost effective to invest in policy makers that reduce maternal mortality in the most efficient manner possible. ${ }^{8}$

Regarding the most risky time for maternal death, it seems that the most maternal deaths occur between third trimester and the first week after delivery. This risk is extremely high on the first and second days after delivery. ${ }^{3,9}$ These findings provide strong support for prioritization of strategies that focus on professional intrapartum care.

There are three types of delay in emergency care for the pregnant women according to the framework presented by Thaddeus and Maine. ${ }^{10}$ The first delay is that delay caused by family and woman to recognize the need for medical help. The second delay is caused because of the late referral, so the woman arrives at the hospital too late to get a benefit from emergency care. The third delay is that due to the delay in receiving effective interventions after arriving at the hospital. ${ }^{11}$ Avoidable causes of maternal deaths are referred to as departure from the standard of satisfactorily accepted care by the woman, practitioner or institution/expected at a particular level of care, which may have contributed to the death. ${ }^{12}$

In this study, we estimated the maternal mortality burden in the tertiary care hospital in Gujarat. Our aim was to search for the causes of maternal deaths, calculate the maternal mortality ratio and identify the avoidable causes and demographic factors for maternal mortality.

\section{METHODS}

This is a retrospective observational study conducted at P.D.U. medical college, which is the largest maternal tertiary care centre in Saurashtra region providing health services. Data were collected from the Facility Based Maternal Death Review Form of pregnant women admitted to the hospital. Inclusion criteria were death of a pregnant woman while she was pregnant or within 42 days from giving birth, whether she was delivered inside or outside our hospital. The number of live births in the same period was obtained from the hospital logbooks.
Data analysis was carried out, and the maternal mortality ratio was measured by dividing the number of maternal deaths by the number of live births during the period of the study multiplied by 100,000 . The data obtained were compared and analysed using SPSS Inc., (Statistical program for social science Inc.,) .Variables was expressed as frequency and percentage. Chi-square test was used to compare variables. Level of significance "P" value was evaluated, where $P$ value $<0.05$ was considered statistically significant.

\section{RESULTS}

Table 1: Demographic characteristics for maternal deaths in the study period.

\begin{tabular}{|ll|}
\hline Age (years) & No. $(\mathbf{n}=120)$ \\
\hline$<20$ & $14(11.6 \%)$ \\
\hline $21-29$ & $75(62.5 \%)$ \\
\hline$>30$ & $21(17.5 \%)$ \\
\hline Residence & \\
\hline Urban & $49(40.8 \%)$ \\
\hline Rural & $71(59.1 \%)$ \\
\hline Booked & $69(42.5 \%)$ \\
\hline Unbooked & $51(57.5 \%)$ \\
\hline Parity & \\
\hline Primi & $36(30 \%)$ \\
\hline Second and third gravida & $58(21.6 \%)$ \\
\hline Multigravida & $26(48.3 \%)$ \\
\hline
\end{tabular}

During the period of the study, a total of 85535 pregnant women were admitted to P.D.U. medical college, Obstetrics and Gynaecology, P.D.U. medical college. The total number of live births was 31456. One-hundred and twenty cases of maternal deaths were identified during study period. The leading cause of death in the 5 years was uncontrollable postpartum haemorrhage (23.3\%), preeclampsia with its complications (15.8\%), Anemia (14.1\%), Abruption placentae $12.5 \%$ and Septicaemia $5 \%$. Direct maternal deaths accounted for $70.7 \%$ of all maternal deaths while $29.3 \%$ of maternal deaths were due to indirect causes.

\section{Maternal age}

When we analysed the demographic characteristics of maternal deaths we found that the mean age of maternal deaths were 25.99 years. Around $62 \%$ of maternal deaths took place in age group of 21-29 while $17.5 \%$ deaths occurred in age group more than 3o years. Around $11 \%$ of deaths occurred in age group $<20$ years. The mean parity of maternal deaths was 2.45 .

\section{Residence}

Regarding the place of residence of the mothers, rural areas had a higher prevalence of maternal death compared to urban areas. Of all maternal deaths $59.1 \%$ 
occurred in women who resided in rural areas while the remaining $40.8 \%$ of mothers resided in urban. Maternal deaths among women who live in rural areas were also significantly higher than those who lived in urban areas.

Table 2: Distribution of maternal deaths regarding time, mode of delivery and pregnancy outcome in the study period.

\begin{tabular}{|ll|}
\hline Time of death & No. $(\mathbf{n}=120)$ \\
\hline Antenatal & $33(27.5 \%)$ \\
\hline Intranatal & $06(5 \%)$ \\
\hline Postnatal & $81(67.5 \%)$ \\
\hline Route of delivery & \\
\hline Vaginal & 65 \\
\hline C- Section & 17 \\
\hline Pregnancy outcomes & \\
\hline Live births & 49 \\
\hline Still birth/abortions & 38 \\
\hline
\end{tabular}

Table 3: Causes of maternal deaths in study.

\begin{tabular}{|ll|}
\hline Cause of death & No. $(\mathrm{n}=120)$ \\
\hline PPH & 28 \\
\hline Eclampsia & 19 \\
\hline Anemia & 17 \\
\hline Abruptio placentae & 15 \\
\hline Hepatitis/ hepatic encephalopathy & 09 \\
\hline Embolism & 08 \\
\hline Septicemia & 06 \\
\hline H1N1 Influenza & 06 \\
\hline Cardiac failure & 06 \\
\hline Malaria & 04 \\
\hline Anaphylactic reaction & 01 \\
\hline Pneumonitis with septicemia & 01 \\
\hline
\end{tabular}

\section{Time of death}

We evaluated the time of death in three categories: 1) during pregnancy 2) during delivery 3) postpartum. Majority of deaths $(67.5 \%)$ in study period occurred postpartum followed by $27.5 \%$ during pregnancy. The lowest figure of death belonged to the time of delivery with $5 \%$.

\section{Birth outcomes}

After exclusion of deaths which occurred during pregnancy, the birth outcome was categorized as live birth and stillbirth. Of all deliveries, 49 resulted in live births. Stillbirth was observed 38 of the cases.

\section{Prenatal care}

Obtained results showed that only $42 \%$ of the mothers had partial or complete access to prenatal care during their pregnancies which included gynaecologist or midwifery visits, sonography during pregnancy and complementary supports. $57.5 \%$ of the mothers had not taken single antenatal visit at any level.

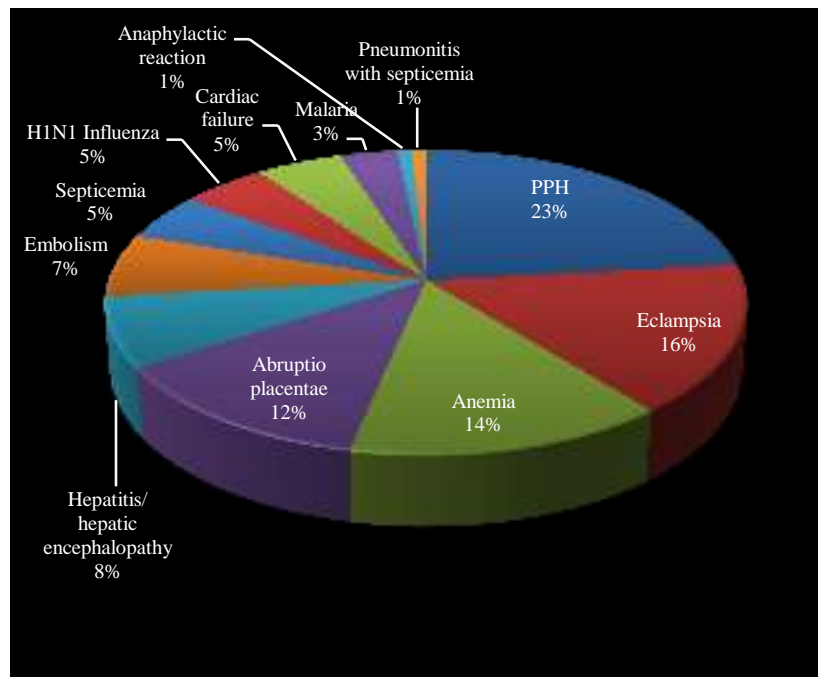

Figure 1: Causes of maternal deaths and its percentages.

Table 4: Analysis of cause of death.

\begin{tabular}{|ll|}
\hline PPH & Cases $\mathbf{n = 2 8}(\mathbf{2 3 . 3 \%})$ \\
\hline Vaginal delivery & 22 \\
\hline Rural & 18 \\
\hline Referred cases & 18 \\
\hline multigravida & 10 \\
\hline Eclampsia & Cases $\mathbf{n = 1 9}(\mathbf{1 5 . 8 \%})$ \\
\hline Referred cases & 13 \\
\hline Unawareness of danger signs & 13 \\
\hline Rural area & 13 \\
\hline Unbooked cases & 06 \\
\hline Anemia & Cases $\mathbf{n = 1 7}(\mathbf{1 4 . 1 \%})$ \\
\hline Referred cases & 15 \\
\hline Unbooked cases & 12 \\
\hline Rural area & 11 \\
\hline Abruptio placentae & Cases $\mathbf{n = 1 5}(\mathbf{1 2 . 5 \%})$ \\
\hline Rural cases & 10 \\
\hline $\begin{array}{l}\text { Unawareness of danger } \\
\text { signs }\end{array}$ & 09 \\
\hline Referred cases & 09 \\
\hline Unbooked cases & 08 \\
\hline multigravida & 05 \\
\hline
\end{tabular}

Twenty eight $(23.3 \%)$ maternal deaths occurred because of PPH. out of 28, 18 cases were referred from rural area and 22 cases had vaginal delivery. So, skilled obstetrics care at rural level reduces the mortality rate by practicing AMTSL and uterotonics.

Eclampsia is the $2^{\text {nd }}$ common cause of mortality in our study. Thirteen cases were referred from rural area and they were unaware of danger signs. Improving antenatal 
care and identification of high risk cases and improving awareness about danger signs reduces mortality.

Eleven cases out of seventeen cases of anaemia belong to rural area and they had not taken any pre-natal visit or haematinics. Prenatal care and iron supplementation reduces anaemia in pregnancy and its complications.

Around 12\% maternal mortality occurred because of abruption placentae. Improving awareness about danger signs and early referral of high risk patients reduces mortality because of abruption.

\section{DISCUSSION}

Developing countries account for 99\% (284 000) of the global maternal deaths reported in 2010 , the majority of which are in sub-Saharan Africa (162 000). Global MMR declined from 400 maternal deaths per 100000 live births in 1990 to 2010 in 2010. The MMR in developing regions is 240 maternal deaths per 100000 live births which were 15 times higher than in developed regions; only 16 deaths per 100,000 live births. ${ }^{4}$

There were four major causes of maternal death: hypertensive disorders, obstetric hemorrhage (mainly postpartum hemorrhage), infections and obstructed labor. In addition, it was found that women also die because of poor nutritional status at conception and because the substandard care provided to them. Current studies show that maternal deaths in developing countries could be reduced if all pregnant women could receive an emergency care of good quality. ${ }^{13}$

This coincides with the results obtained from our study, as we found that the leading cause of death in the 5 years was uncontrollable postpartum haemorrhage (23.3\%), preeclampsia with its complications (15.8\%), Anemia (14.1\%), Abruption placentae $12.5 \%$ and Septicaemia $5 \%$. Hepatic disorders accounted for $8 \%$ of maternal deaths especially acute fulminant hepatitis, while embolism disorders $7 \%$.

We detected three main factors that contributed to maternal deaths in P.D.U. medical college and hospital and both could be avoided: first was the inadequate antenatal care, unawareness of danger signs, lack of birth preparedness. The second factor was delayed transfer from the private clinics, primary or secondary health care hospitals. Third factor was lacking in staffing and difficulties in communication between departments involved in the management of these cases, such as the intensive care unit, medicine and surgical department, and blood bank.

Maternal mortality studies showing differences between urban and rural areas especially in the poor countries In our study there were significant difference in maternal mortality among rural areas; 71 cases versus 49 cases only in urban areas. This can be attributed to poverty and lack of transfer facilities from far villages, besides the higher rates of illiteracy among people than those living in urban areas.

Most maternal deaths seem to occur between the third trimester and the first week after the end of pregnancy.3, 9 Mortality is extremely high on the first and second days after birth. The results obtained from our study coincided with the published data. $81(67.5 \%)$ cases out of 120 cases died during postpartum period. These findings provide strong support for prioritization of strategies that focus on professional intrapartum and postpartum care.

The first delay, which is the delay caused by family and woman to recognize the need for medical help can be avoided by increasing the community awareness, by informing the pregnant woman about risks of her pregnancy and encouraging her to receive antenatal care. This will help in decreasing most of the direct and indirect causes of maternal deaths.

The second delay because of late referral, can be prevented by improving health system especially primary care centers, ambulance services and infrastructure which is some sort difficult and need long-term national plan.

One of the limitations of our study that it only reflects the cases that were brought to our hospital and thus may be a biased sample of the general population making our data not completely generalizable.

Saving maternal lives is a matter of human right and equality and as Professor Mahmoud Fathalla, past president of the international federation of obstetricians and gynaecologists and former chair of the WHO advisory committee on health research, said: "women are not dying because of untreatable diseases. They are dying because societies have yet to make the decision that their lives are worth saving."

\section{CONCLUSION}

Preeclampsia and postpartum haemorrhage are still the most two leading causes of death in developing countries. Moreover, there were three major contributing factors in these deaths: Unawareness of antenatal care and danger signs, the substandard care and delayed transfer of cases; both are avoidable. Efforts should be made to ensure that all deliveries occur with the help of skilled personnel.

Most of the deaths could have been avoided with good antenatal, intranatal and postnatal care, early referral, quick, efficient and well equipped transport facilities, availability of adequate blood and blood components, and promotion of overall safe motherhood.

Despite wide recognition of evidence based interventions and the availability of information and guidelines, major gaps remain in implementation. 
Maternal mortality can be averted by implementation of 3E's - Emergency obstetric care, early risk screening and efficient obstetric service.

Analysis of every maternal death through maternal death audit should be carried out. Community participation is more necessary. Awareness of birth control measures, sex education in adolescence can reduce deaths due to septic abortion.

Maternal death audit will help in identifying the actual cause of maternal deaths and deficiencies in health care delivery system that might contribute in formulating preventive measures to reduce pregnancy related deaths.

Funding: No funding sources

Conflict of interest: None declared

Ethical approval: The study was approved by the Institutional Ethics Committee

\section{REFERENCES}

1. World health organization. ICD-10: international statistical classification of diseases and related health problems. Geneva: world health organization; 1992.

2. Høj L, da Silva D, Hedegaard K, Sandstrom A, Aaby P. Maternal mortality: only 42 days? BJOG 2003;110(11):995-1000.

3. Ronsmans C, Graham WJ. Maternal mortality: who, when, where, and why. Lancet. 2006;368:1189-200.

4. World health organization. Trends in maternal mortality: 1990 to 2010: WHO, UNICEF, UNFPA and the world bank estimates. Geneva: world health organization; 2012

5. Buekens P. Is estimating maternal mortality useful? Bull world health organ. 2001;79(3):179.

6. Kassebaum NJ, Villa AB, Coggeshall MS, Shackelford KA, Steiner C, Heuton KR, et al. Global, regional, and national levels and causes of maternal mortality during 1990-2013: a systematic analysis for the global burden of disease study 2013. Lancet. 2014;384:980-1004.

7. Jowett M. Safe motherhood interventions in lowincome countries: an economic justification and evidence of cost effectiveness. Health policy. 2000;53:201-28.
8. Khan KS, Wojdyla D, Say L, Gulmezoglu AM, Van Look PF. WHO analysis of causes of maternal death: a systematic review. Lancet. 2006;367:1066-74.

9. Li XF, Fortney JA, Kotelchuck M, Gloyer LH. The postpartum period: the key to maternal mortality. Int J Gynecol Obstet. 1996;54(1):1-10.

10. Thaddeus S, Maine D. Too far to walk: maternal mortality in context. Soc Sci Med. 1994;38:1091110.

11. McCarthy J, Maine D. A framework for analyzing the determinants of maternal mortality. Stud Fam Plann. 1992;23(1):23-33.

12. Fawcus S, Mbizvo M, Lindmark G, Nystrom L. A community-based investigation of avoidable factors for maternal mortality in Zimbabwe. Stud Fam Plann. 1996:319-27.

13. Paxton A, Maine D, Freedman L, Fry D, Lobis S. The evidence for emergency obstetric care. Int $\mathrm{J}$ Gynecol Obstet. 2005;88:181-93.

14. El-Henawy A. Current situation, progress and prospects of health for all in Egypt. East Mediterr Health J. 2000;6(4):816-21.

15. Egypt $\mathrm{MoH}$, Population. National maternal mortality study: Egypt 2000: report of findings and conclusions. Egypt: directorate of maternal and child health care, ministry of health and population; 2001.

16. Karlsen S, Say L, Souza JP, Hogue CJ, Calles DL, Gulmezoglu AM, et al. The relationship between maternal education and mortality among women giving birth in health care institutions: analysis of the cross sectional WHO global survey on maternal and perinatal health. BMC Public Health. 2011;11:606.

17. Gabrysch S, Campbell OM. Still too far to walk: literature review of the determinants of delivery service use. BMC pregnancy and childbirth. 2009;9:34.

18. Fathalla MF. Human rights aspects of safe motherhood. Best Pract Res Clin Obstet Gynaecol. 2006;20(3):409-19.

Cite this article as: Patel M, Goswami K, Prajapati $\mathrm{S}$, Chavda D. A five years retrospective analytic study of maternal deaths at tertiary care centre, Gujarat, India. Int J Reprod Contracept Obstet Gynecol 2016;5:2823-7. 